\title{
CHANGES OF DRAW RATIOS OF PLASTIC TUBES ON A CONICAL MANDREL
}

\author{
By Michio Sudo ${ }^{* 1}$ and Shoji Ichihara ${ }^{* 2}$ \\ *1 (Nikko Resin Co., Ltd., Kamikasuya, Isehara 259-11) \\ *2 (Central Research Laboratory, Mitsubishi Petrochemical Co., Ltd., \\ Ami, Inashiki, Ibaraki 300-03)
}

\section{Synopsis}

Tubes of high density polyethylene were drawn with a conical mandrel. The changes of the draw ratios on the mandrel in the longitudinal direction of the tubes (the machine direction, MD) and in the hoop direction (the transverse direction, TD) were measured. The change of the draw ratio in the $\mathrm{TD}, \lambda_{2}$, is almost completely determined by the diameter and shape of the mandrel. At the early stage of mandrel drawing, the draw ratio in the MD, $\lambda_{1}$, decreased with increasing $\lambda_{2}$ and then suddenly began to increase. Namely, $d \lambda_{1} / d \lambda_{2}$ was negative at first, and then it became positive. In almost all regions of $d \lambda_{1} / d \lambda_{2}>0, d^{2} \lambda_{1} / d \lambda_{2}{ }^{2}$ was negative.

\section{INTRODUCTION}

The idea of drawing the tubes of polymeric materials by using conical mandrels is not new. Wessling and Alfrey have calculated the draw ratios of elastic tubes on the conical mandrels in the longitudinal direction of the tubes (the machine direction, MD) and in the hoop direction of the tubes (the transverse direction, TD). ${ }^{1)}$ Their results show that the draw ratio in the MD, $\lambda_{1}$, decreases with increasing draw tatio in the TD, $\lambda_{2}$. It passes through a minimum value and then it begins to increase with increasing $\lambda_{2}$.

Further, when the calculated $\lambda_{1}$ is plotted against $\lambda_{2}$, the curves are concave in shape, namely $d^{2} \lambda_{1} / d \lambda_{2}^{2}>0$. Wessling and Alfrey have also shown the experimental results of drawing vulcanized rubber tubes with conical mandrels. Their experimental results show a similar tendency as described above, though their figures deviate noticeably from the calculated results in the large deformation region. Gutteridge have also calculated the draw ratios, $\lambda_{1}$ and $\lambda_{2}$ of elastic and visco-elastic tubes on conical mandrels. ${ }^{2}$ His results are basically similar to those of Wessling and Alfrey though there are some differences.

The process of drawing plastic tubes with conical mandrels is a very interesting one from a practical point of view because it is one of the simplest drawing processes for plastic films. However up to the present, it has not been widely applied in industry. We have developed a drawing process for high density polyethylene (HDPE) tubes using conical mandrels, and reported the outline of our process, ${ }^{3,4}$. The necessary condition which the HDPE tubes must have before drawing have also been reported. ${ }^{5,6)}$

In this paper, we show our experimental results concerning changes of the draw ratios in the TD, $\lambda_{2}$, and in the MD, $\lambda_{1}$ of HDPE tubes on conical mandrels.

\section{EXPERIMENTAL}

\subsection{Description of the process}

The process developed by us is not only a drawing process for tubular film in the TD, but it also includes an in-line process for laminating the TD stretched tubular film with the extruded tubular film oriented in the MD. The laminated tubes obtained by our process have been named "Sudex" Sudex basically consists of a TD oriented inner layer, an MD oriented outer layer and a middle layer for adhesion. Usually, the inner layer is made of HDPE. The middle layer is made of ethylene-vinylacetate copolymer. The outer layer is made of low density polyethylene, HDPE or a blend of the two.

Figure 1 shows a schematic diagram of the 


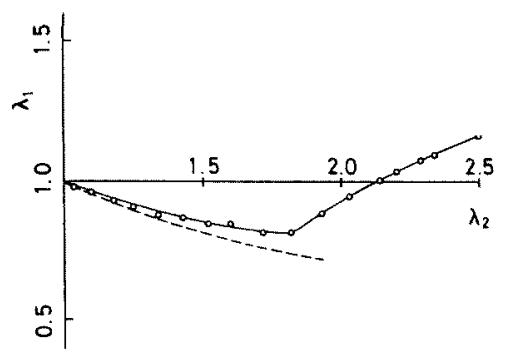

Fig. 2. Relations between draw ratios in the MD, $\lambda_{1}$, and in the TD, $\lambda_{2}$, on the mandrel with the cone angle $\theta=55^{\circ}$ The final draw ratio in the $\mathrm{TD}, \lambda_{21}$ was 2.5 . The final draw ratio in the MD, $\lambda_{1 f}$, was about 1.2 . The broken line shows the relation of $\lambda_{1}=$ $1 / \sqrt{\lambda_{2}}$.

larger than $1 / \sqrt{\lambda_{2}}$. Then, after $\lambda_{1}$ passes through a minimum, it increases with increasing $\lambda_{2}$. Before the minimum point, the curve of $\lambda_{1}$ vs. $\lambda_{2}$ is concaved upward. However, after the minimum point, the curve is concaved downward. This shows that initially $d \lambda_{1} / d \lambda_{2}<0$ and $d^{2} \lambda_{1} / d \lambda_{2}^{2}$ $>0$. Then, $d \lambda_{1} / d \lambda_{2}$ becomes positive and $d^{2} \lambda_{1} /$ $d \lambda_{2}^{2}$ negative.

Figure 3 shows the data when $\lambda_{1 f}=1.3,1.5$ and 2.65. In these cases, method $B$ was used for measuring $\lambda_{1}$, and $\lambda_{2}$. It is noted that the curves here and those in Figure 2 show similar patterns. Namely, before the minimum point, $d \lambda_{1} / d \lambda_{2}<0$ and $d^{2} \lambda_{1} / d \lambda_{2}^{2}>0$. And, after the minimum point, $d \lambda_{1} / d \lambda_{2}>0$ and $d^{2} \lambda_{1} / d \lambda_{2}^{2}<0$.

The calculated results for elastic and viscoelastic tubes show that at first $d \lambda_{1} / d \lambda_{2}$ is negative and then it becomes positive but $d^{2} \lambda_{1} / d \lambda_{2}^{2}$ is positive in all regions. Namely, the calculated curves for elastic and the visco-elastic tubes are concaved upward in all regions. The experimental results for vulcanized rubber show that $d^{2} \lambda_{1} / d \lambda_{2}^{2}$ $\geqq 0$ where $d \lambda_{1} / d \lambda_{2}>0$.

Therefore, it is possible to consider that the negative $d^{2} \lambda_{1} / d \lambda_{2}^{2}$ in the regions of the positive $d \lambda_{1} / d \lambda_{2}$ is a feature of these plastic tubes. Further, the reason that $d^{2} \lambda_{1} / d \lambda_{2}^{2}$ becomes negative when $d \lambda_{1} / d \lambda_{2}>0$ may be related to the yielding phenomena of the plastic tubes. We will discuss this point in the coming paper.

Figure 4 shows the relation between $1 / \lambda_{1} \lambda_{2}$ and $\lambda_{2}$ when $\lambda_{1 \mathrm{f}}$ are about 1.2 and 2.65. If the change

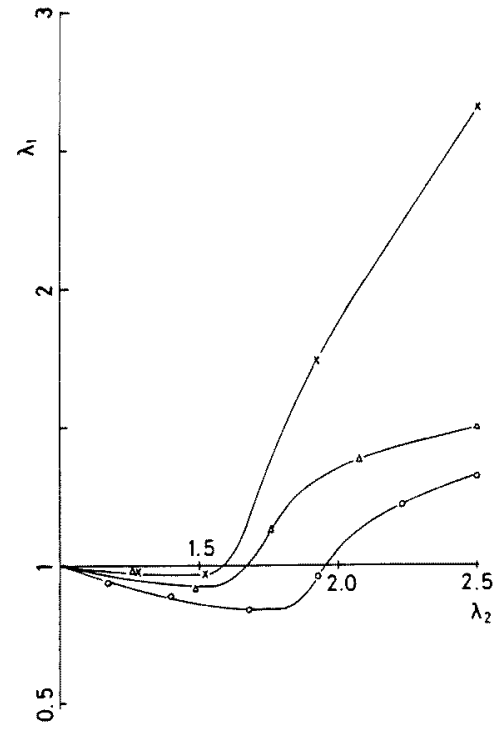

Fig. 3. Relations between $\lambda_{1}$ and $\lambda_{2}, \theta=55^{\circ}$. Final draw ratio in the TD, $\lambda_{2 \mathrm{f}}=2.5$. Final draw ratio in the $M D, \lambda_{1 \mathrm{f}}=1.3(0), 1.5(\Delta)$ and $2.65(x)$.

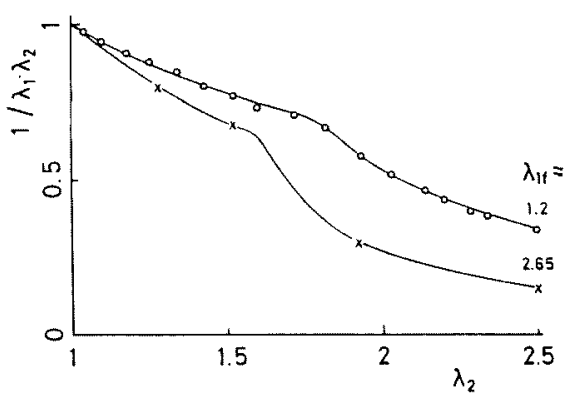

Fig. 4. Relations between $1 / \lambda_{1} \cdot \lambda_{2}$ and $\lambda_{2} . \quad \theta=55$ and $\lambda_{21}=2.5, \lambda_{1 f}=1.2$ and 2.65 .

of the density of the tube in the drawing process is small and negligible, $1 / \lambda_{1} \lambda_{2}$ is equal to the draw ratio in the direction perpendicular to the tube surface, namely in the direction of the film thickness, $\lambda_{3}$. After the minimum value of $\lambda_{1}$ in Fig. 3 has been reached $1 / \lambda_{1} \lambda_{2}$ decreases suddenly with increasing $\lambda_{2}$. As the change of the density in the drawing process is smaller than the errors in the measurement of $\lambda_{1}$ and $\lambda_{2}$, these results indicate that the thickness of the tube decreases suddenly after the minimum of $\lambda_{1}$. 


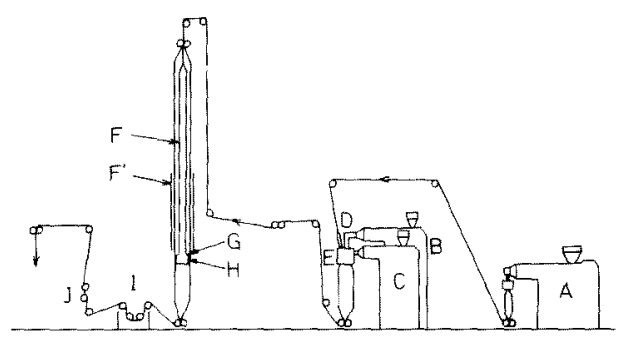

Fig. 1. Outline of Sudex forming process.

Sudex forming process. The inner layer tube is formed by an extruder $A$. The middle and the outer layer tubular films are formed by extruders $B$ and $C$, respectively. The middle and the outer layers are formed by co-extrusion. The inner layer tubular film is introduced into the middle and the outer layers through a hole $\mathrm{D}$ in a coextrusion circular die $\mathrm{E}, \mathrm{F}, \mathrm{G}$ and $\mathrm{H}$ compose a mandrel system for drawing and laminating the inner layer with the middle and the outer layers. $F$ is a cylindrical mandrel used to pre-heat the inner layer tube before drawing. $F^{\prime}$ are infra-red heaters to pre-heat the middle and the outer layers. $G$ is a conical mandrel for drawing the inner layer tube. $H$ is a cylindrical mandrel to laminate the inner layer tube with the middle and the outer layer tubes. To heat the mandrels F, G and $\mathrm{H}$, steam is used. Steam is generated in a water tank located at the bottom of mandrel $H$. The ratio of the diameters of the mandrels $\mathrm{H}$ and $\mathrm{F}$ is equal to the final draw ratio in the hoop direction (in the TD), $\lambda_{2 f}$, of the inner layer tube. The cone angle (namely, the angle between the center line of the mandrel and the slope of the cone) is $55^{\circ}$ The laminated tube is annealed in a bath, I. Surface (corona) treatment is possible by using the roller, $J$, if necessary.

In order to measure the changes of the draw ratios in the MD, $\lambda_{1}$, and in the TD, $\lambda_{2}$, of the inner layer tube on the conical mandrel, the middle and the outer layer tubes are cut off and are removed.

\subsection{Material and treatment before drawing}

The melt index of the HDPE used was 0.04 and its density was $0.955 \mathrm{~g} / \mathrm{cm}^{3}$ The HDPE tubes were extruded from a circular die $20 \mathrm{~mm}$ in diameter. The temperature of the extruded tubes was $200^{\circ} \mathrm{C}$. After being blown up, they were quenched with water after the tubes were cooled down to $116^{\circ} \mathrm{C}$. Thus, HDPE tubes were obtained. Then the tubes were pre-heated with the preheating mandrel. The temperature of the pre-heating mandrel was $114-115^{\circ} \mathrm{C}$. After pre-heating, the tubes were drawn with the conical mandrel. The temperature of the conical mandrel was $119-$ $120^{\circ} \mathrm{C}$.

The final draw ratio in the TD, $\lambda_{2 f}$, is determined by the ratio of the diameters of the top and the bottom of the conical mandrel. $\lambda_{2 f}$ used was 2.5. The final draw ratio in the $\mathrm{MD}, \lambda_{1 f}$, is determined by the ratio of the velocities in the $\mathrm{MD}$ of the tubes before and after drawing. If the velocity of the tube before drawing in the $M D$ is constant, $\lambda_{1 f}$ is determined by that after drawing. As the velocity of the tube after drawing in the $M D$ is equal to the take-up speed of the draw in tube, $\lambda_{\text {If }}$ can be varied by adjusting the take-up speed of the drawn tube if the velocity of the tube in the MD is constant.

\subsection{Measurements of $\lambda_{1}$ and $\lambda_{2}$ on the conical mandrel}

2.3.1 Method A. Cross stripes were marked on the surface of the tube before stretching. The distance between each stripe was $1.5 \mathrm{~cm}$. When the marked part of the tube came onto the conical mandrel, the drawing machine was stopped and the tube on the mandrel was cut off and removed quickly. The change in the distance between each stripe was then measured and the change of $\lambda_{1}$ against $\lambda_{2}$ was calculated. Here, the tube was formed with a blow-up ratio of 7.13 before drawing and $\lambda_{1 f}$ was about 1.2.

2.3.2 Method B. In this method, the distance between each stripe was $2 \mathrm{~cm}$. Photographs were taken of the marked part of the tubes when it came onto the conical mandrel. $\lambda_{1}$ was calculated from the relative displacement of the stripes on the tube surface. $\lambda_{2}$ was calculated from the cone dimensions. Here, the tubes were formed with a blow-up ratio 6.33 before drawing. $\lambda_{11}$ was varied accordingly: $1.3,1.5$ and 2.65 .

\section{RESULTS AND DISCUSSIONS}

Figure 2 shows the relation between $\lambda_{1}$ and $\lambda_{2}$ when $\lambda_{1 \mathrm{f}}=1.2$. In this case, method $\mathrm{A}$ was used for measuring $\lambda_{1}$ and $\lambda_{2}$. At first, decreases with increasing $\lambda_{2}$. In this region, $\lambda_{1}$ is slightly 
When the extrusion conditions and therefore the mechanical properties of the tubes before drawing are not met, tubes can be broken on the conical mandrel. In most cases, direction of the fractures is in the hoop direction. Fractures of this type seem to be related to the abrupt decrease of the thickness of the tube after the minimum of $\lambda_{1}$. The relation between the stress in the MD, $\sigma_{1 t}$, and that in the TD, $\sigma_{2}$, has been expressed by Eq. $(1)^{3,4)}$

$$
\frac{d\left(\sigma_{1 \mathrm{t}} / \lambda_{1}\right)}{d \lambda_{2}}=(1+\mu \cot \theta) \frac{\sigma_{2 \mathrm{t}}}{\lambda_{1} \lambda_{2}}
$$

where $\sigma_{1 t}$ and $\sigma_{8 \mathrm{t}}$ are the stresses per unit area of the cross sections in each direction of the tube under drawing, $\mu$ is the friction coefficient between the tube and the conical mandrel and $\theta$ is the cone angle. A much simpler representation of Eq. (1) in terms of the nominal stresses in the MD, $\sigma_{1}$, and that in the TD, $\sigma_{2}$, is ${ }^{6}$ )

$$
\frac{d \sigma_{1}}{d \lambda_{2}}=(1+\mu \cot \theta) \frac{\sigma_{2}}{\lambda_{1}}
$$

where $\sigma_{1}$ and $\sigma_{2}$ are the stresses per unit area of the cross sections of the tube before drawing in the MD and in the TD, respectively. To derive these equations, it is supposed that $\lambda_{1} \lambda_{2} \lambda_{3}=1$. In Eq. (2), $\cot \theta$ is a positive constant. $\sigma_{2}$ is positive and is determined by $\lambda_{2}$ and the drawing rate. $\boldsymbol{\mu}$ is positive but its value may change slightly during the drawing on the mandrel. $\lambda_{1}$ must also be positive. The change of $\lambda_{2}$ on the mandrel must be positive because the tube move in a forward direction. Therefore, the change of $\sigma_{1}$ must be positive because all other terms in Eq. (2) are positive. Further, supposing that the change of $\mu$ is small, when $d \sigma_{1} / d \lambda_{2}$ becomes small suddenly by yielding, $\lambda_{1}$ increases and $\lambda_{3}=1 / \lambda_{1} \lambda_{2}$ decreases abruptly. The results shown in Figures 2 , 3 and 4 seem to show that these considerations are reasonable. Further, if $d \sigma_{1} / d \lambda_{2}$ becomes too small abruptly, the thickness of the tube decreases too suddenly and the tube will be broken in the TD. In other words, it is necessary that the tube, before drawing must be oriented in the MD adequately and it does not show a remarkable yielding in the MD.

\section{REFERENCES}

1) R. A. Wessling and T. Alfrey, Jr., Trans. Soc. Rheol, 8, 85 (1964)

2) P. A. Gutteridge, J. Non-Newtonian Fluid Mechanics, 4, 73 (1978)

3) M. Sudo and S. Ichihara, TAPPI Paper Synthetics Conference Proceedings, 285 (1979)

4) M. Sudo and S. Ichihara, Kobunshi Ronbunshu, 38, 343 (1981)

5) M. Sudo and S. Ichihara, ibid., 38, 497 (1981)

6) M. Sudo, ibid., 39, 59 (1982)

円錐型マンドレル上のプラスチックチューブの 延伸倍率の変化

\section{日交レジン株式会社 須藤道雄} 三菱油化怢式会社中央研究所 市原祥 次

円錐型マンドレルによるチューブ状フィルムの延伸プ ロセスを開発し ${ }^{3 \sim 6)}$ ，円錐マンドレル上での高密度ポリ エチレンの繸方向及び円周方向への延伸倍率の变化を測 定した。繸延伸倍率 $\lambda_{1}$ 蚛丹周方向の延伸倍率 $\lambda_{2}$ の增加 と其に先ず減少し，次いで增加する。 $d \lambda_{1} / d \lambda_{2}<0$ の領

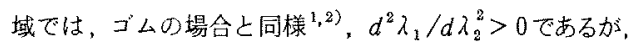
$d \lambda_{1} / d \lambda_{2}>00$ 濞域ではゴムの場合之異なり $d^{2} \lambda_{1} / d \lambda_{2}^{2}$ く0乞なることを見出した。降伏点後の継方向の㤁力の 增加が小さいと， $\lambda_{1}$ の極小点直後の $d \lambda_{1} / d \lambda_{2}$ は大きく なり，破断しやすくなると考えられる。 